\title{
Development of PCR-based markers and whole-genome selection model for anthracnose resistance in white lupin (Lupinus albus L.)
}

\author{
Sandra Rychel-Bielska ${ }^{1,2}$ (D) Nelson Nazzicari ${ }^{3} \cdot$ Piotr Plewiński $^{2}$ (D) $\cdot$ Wojciech Bielski ${ }^{2}$ (D) $\cdot$ Paolo Annicchiarico $^{3}$ (D) \\ Michał Książkiewicz ${ }^{2}$ (D)
}

Received: 11 July 2020 / Revised: 7 September 2020 / Accepted: 14 September 2020 / Published online: 23 September 2020

(C) The Author(s) 2020

\begin{abstract}
White lupin (Lupinus albus L.) is a high-protein grain legume crop, grown since ancient Greece and Rome. Despite long domestication history, its cultivation remains limited, partly because of susceptibility to anthracnose. Only some late-flowering, bitter, low-yielding landraces from Ethiopian mountains displayed resistance to this devastating disease. The resistance is controlled by various genes, thereby complicating the breeding efforts. The objective of this study was developing tools for molecular tracking of Ethiopian resistance genes based on genotyping-by-sequencing (GBS) data, envisaging linkage mapping and genomic selection approaches. Twenty GBS markers from two major quantitative trait loci (QTLs), antr04_1/antr05_1 and antr04_2/antr05_2, were converted to PCR-based markers using assigned transcriptome sequences. Newly developed markers improved mapping resolution around both anthracnose resistance loci, providing more precise QTL estimation. PCR-based screening of diversified domesticated and primitive germplasm revealed the high specificity of two markers for the antr04_1/ antr05_1 locus (TP222136 and TP47110) and one for the antr04_2/antr05_2 locus (TP338761), highlighted by simple matching coefficients of 0.96 and 0.89 , respectively. Moreover, a genomic selection approach based on GBS data of a recombinant inbred line mapping population was assessed, providing an average predictive ability of 0.56 . These tools can be used for preselection of candidate white lupin germplasm for anthracnose resistance assays.
\end{abstract}

Keywords White lupin · Marker-assisted selection · Genomic selection · Anthracnose resistance $\cdot$ Quantitative trait

Communicated by: Izabela Pawłowicz

Electronic supplementary material The online version of this article (https://doi.org/10.1007/s13353-020-00585-1) contains supplementary material, which is available to authorized users.

Michał Książkiewicz

mksi@igr.poznan.pl

1 Department of Genetics, Plant Breeding and Seed Production, Wroclaw University of Environmental and Life Sciences, Plac Grunwaldzki 24A, 50-363 Wrocław, Poland

2 Institute of Plant Genetics, Polish Academy of Sciences, Strzeszyńska 34, 60-479 Poznań, Poland

3 CREA-FLC, Council for Agricultural Research and Economics, Research Centre for Fodder Crops and Dairy Production, Viale Piacenza 29, 26900 Lodi, Italy

\section{Introduction}

Lupins are valuable crops appreciated as a source of protein for food and feed, as well as plants enhancing mobilization of soil phosphorus, improving soil fertility through symbiotic nitrogen fixation, and increasing economic payback for succeeding crops (Lambers et al. 2013). The seed of modern white lupin (Lupinus albus L.) germplasm is characterized by high content of protein, around $38-42 \%$ on a dry-weight basis (Papineau and Huyghe 2004); moderate content of oil, around 10-12\% (Annicchiarico et al. 2014) with outstanding food quality (Boschin et al. 2007); and low alkaloid content (Lin et al. 2009). Moreover, extracts from different lupin species were revealed to have antimicrobial activity (Confortin et al. 2018; Confortin et al. 2017; Confortin et al. 2019; Erdemoglu et al. 2007; Romeo et al. 2018). During the domestication process, germplasm resources with dwarf architecture determinate growth habit and higher cold tolerance have also been 
selected (Harzic et al. 1995; Huyghe and Papineau 1990; Julier et al. 1993). Moreover, the assay of 121 entries representing the global white lupin germplasm revealed that potentially high-yielding landraces are available for exploitation in breeding programs (Annicchiarico et al. 2010). However, worldwide attempts of white lupin improvement have been hampered by high susceptibility to anthracnose, caused by the pathogenic fungus, Colletotrichum lupini (Bondar) Nirenberg, Feiler \& Hagedorn (Nirenberg et al. 2002). Typical symptoms were observed as early as in 1912 in Brazil, but the underlying fungus was identified three decades later (Weimer 1943). Early screening of the resistance revealed some level of resistance in L. angustifolius and $L$. luteus germplasm and high susceptibility of all $L$. albus accessions tested (Weimer 1952). The appearance of the disease on white lupins in France (1982) and Ukraine (1983) has challenged dramatically the European white lupin breeders (Gondran et al. 1996). Soon afterwards, anthracnose appeared worldwide in nearly all regions where white lupins are cultivated, including major producers such as Australia, Poland, and Germany (Frencel 1998; Frencel et al. 1997; Sweetingham et al. 1995; Talhinhas et al. 2016). Anthracnose susceptibility is a more important issue in white lupin than in the narrow-leafed lupin, because the latter has several independent sources of resistance already present in improved germplasm (Boersma et al. 2005; Fischer et al. 2015; Yang et al. 2004; Yang et al. 2008). This disease proved to be a critical obstacle for the agronomic improvement of white lupin, as the only source of resistance, located in a mountainous region of Ethiopia, has been identified hitherto (Phan et al. 2007) in the form of several accessions collected in one district (Adhikari et al. 2009). Recent studies revealed that Ethiopian germplasm landraces carry rare alleles and are relatively uniform genetically (Atnaf et al. 2017; Raman et al. 2014).

The lack of modern breeding tools hampered the rate of white lupin genetic improvement. Breeders have spent more than two decades to harness Ethiopian anthracnose resistance alleles with very limited success rate: only a few cultivars showing an incremental improvement of anthracnose resistance were bred (Adhikari et al. 2009; Adhikari et al. 2013; Jacob et al. 2017; Talhinhas et al. 2016). Molecular genomic resources of white lupin include two mapping populations with associated low-density linkage maps (Croxford et al. 2008; Phan et al. 2007; Vipin et al. 2013) and a draft transcriptome assembly (O'Rourke et al. 2013). Some sequence tagged site (STS) markers linked to low alkaloid content (PauperM1) and anthracnose resistance (WANR1, WANR2 and WANR3) (Lin et al. 2009; Yang et al. 2010) were developed, but the recombination rate between these markers and corresponding trait loci was too high for their implementation in marker-assisted selection. The reference recombinant inbred line (RIL) mapping population developed from the cross
Kiev Mutant (Ukraine) $\times$ P27174 (Ethiopia) segregates for many agronomic traits, including also the resistance to anthracnose inherited from Ethiopian parents (Phan et al. 2007). Trait loci have been localized on the linkage map (Cowley et al. 2014; Phan et al. 2007; Vipin et al. 2013), but low marker density, namely one marker per $10.8 \mathrm{cM}$ (Phan et al. 2007) and one per $4.6 \mathrm{cM}$ (Vipin et al. 2013), impeded quantitative trait loci (QTL) mapping attempts. Recently, genotyping-by-sequencing (GBS) data were exploited to develop a new high-density consensus linkage map of the species based on new, transcriptome-anchored markers (Książkiewicz et al. 2017). Mapping of white lupin QTLs revealed polygenic control of anthracnose resistance and provided a bunch of allele-sequenced markers tagging these QTLs, opening new possibilities for development of tools for molecular tracking of anthracnose resistance. For traits controlled by various genes, an alternative approach to marker-assisted selection is represented by genomic selection, by which major and minor gene effects are taken into account by a statistical model for breeding value prediction that is constructed from the joint analysis of phenotyping and genotyping data of a germplasm sample that represents well the target genetic base (Heffner et al. 2009; Meuwissen et al. 2001). The first investigations of genomic selection for white lupin revealed high ability to predict grain yield in contrasting European environments (Annicchiarico et al. 2019) and several morphophysiological and agronomic traits in Northern Italy (Annicchiarico et al. 2020).

The present paper aims to exploit the molecular information generated by markers (Książkiewicz et al. 2017) to develop PCR-based array tagging two major white lupin anthracnose resistance QTLs, ultimately facilitating preselection of germplasm carrying candidate Ethiopian alleles of anthracnose resistance genes. As an additional objective, we assessed preliminarily the applicability of a genomic selection approach for prediction of anthracnose resistance based on GBS data of a mapping population.

\section{Materials and methods}

\section{Transformation of GBS polymorphisms to PCR-based markers}

To select reference transcript sequences for primer design, GBS marker sequences from QTL loci (Książkiewicz et al. 2017) were aligned to assembled transcriptomes of Kiev and P27174 lines as well as to reference white lupin gene index LAGI01 (O'Rourke et al. 2013) by BLAST (Altschul et al. 1990) implemented in the Geneious software (Kearse et al. 2012) under an $e$-value cut-off of $1 \mathrm{e}^{-10}$. Selected transcripts were then aligned to the genome sequence of the narrow-leafed lupin (Hane et al. 2017) under an $e$-value 
cut-off of $1 \mathrm{e}^{-15}$, extracting matching regions with context size of $5000 \mathrm{nt}$. To find exon/intron boundaries, extracted narrow-leafed lupin genome regions were assembled together with white lupin GBS and transcript sequences into contigs using progressive Mauve algorithm (Darling et al. 2004) assuming genome collinearity. Mauve alignments consisting of corresponding markers, L. albus Kiev, P27174 and LAGI01 transcripts and L. angustifolius scaffolds were screened for the presence of polymorphic loci. The primers flanking these loci were designed using Primer3Plus (Untergasser et al. 2007) and L. albus cDNA sequences as templates. DNA was isolated from $L$. albus Kiev and P27174 using DNeasy Plant Mini Kit (Qiagen, Hilden, Germany) and ethyl alcohol $(96 \%,<0.1 \%$ methanol, Avantor Performance Materials, Gliwice, Poland). Amplification was performed using GoTaq® Flexi DNA Polymerase (Promega, Madison, USA) and Labcycler Gradient thermal cycler (Sensoquest, Göttingen, Germany). Ninety-six-well PCR plates (4titude, Wotton, Surrey, UK) and standard tips (Neptune Scientific, San Diego, USA) were used. Amplicons were purified directly from the post-reaction mixtures (QIAquick PCR Purification Kit; Qiagen) and sequenced (ABI PRISM 3130 XL Genetic Analyzer; Applied Biosystems, Hitachi) in the Laboratory of Molecular Biology Techniques, Faculty of Biology, Adam Mickiewicz University (Poznan, Poland). Nucleotide substitution polymorphisms were resolved by the cleaved amplified polymorphic sequence (CAPS) (Konieczny and Ausubel 1993) or derived CAPS (dCAPS) (Neff et al. 1998) approaches. Restriction sites and dCAPS primers were identified using dCAPS Finder 2.0 (Neff et al. 2002) and SNP2CAPS (Thiel et al. 2004). Restriction enzymes were supplied by New England Biolabs (Ipswich, USA) and Thermo Fisher Scientific (Waltham, USA), depending on price and availability. Restriction products were separated by agarose gel electrophoresis (Wide Range Agarose, Serva, Heidelberg, Germany) with the agarose concentration (1-3\%) adjusted to follow the size of the expected digestion products. Standard Tris-Borate-EDTA buffer was exploited (Serva). Electronic expandable multichannel pipette (Matrix, Thermo Fisher Scientific) was used for transfers of samples between PCR plates and gels. Data on developed molecular markers, including primer sequences, annealing temperature, nucleotide sequence identity, and polymorphic loci are provided in Tables 1 and 2 as well as in the Supplementary Table S1.

\section{Linkage mapping}

Genetic mapping was performed using the reference Kiev $\mathrm{x}$ $\mathrm{P} 27174 \mathrm{~F}_{8}$ recombinant inbred line (RIL) population $(n=196)$ delivered by the Department of Agriculture and Food Western
Australia. This population was derived from a cross between the anthracnose-resistant Ethiopian landrace P27174 and susceptible Ukrainian line Kiev Mutant (Phan et al. 2007). Kiev Mutant-like scores were assigned as $b$, P27174-like scores as $a$, and heterozygotes as $h$.

Chi-square $\left(\chi^{2}\right)$ values for Mendelian segregation in $\mathrm{F}_{8}$ RILs were estimated using the following expected segregation ratios: 0.4961 (Kiev Mutant), 0.4961 (P27174), and 0.0078 (heterozygote). The calculation of probability was based on $\chi^{2}$ and 2 degrees of freedom. L. albus marker segregation files (Książkiewicz et al. 2017; Phan et al. 2007; Vipin et al. 2013), together with those developed in this study, were imported to JoinMap 4.1 (Stam 1993). Multipoint mapping was performed after grouping under independence LOD of 11.0 (parameters in the Supplementary Table S2). Linkage group optimization was performed according to the procedure described by Książkiewicz et al. 2017.

The Pearson product-moment correlation coefficient between averaged anthracnose disease resistance scores (Książkiewicz et al. 2017) and marker allelic phases for the set of 191 mapping population lines was calculated in Excel. The $p$ value (both one-tailed and two-tailed probability) of a Pearson correlation coefficient was calculated using the $p$ value calculator for correlation coefficients (http://www. danielsoper.com/statcalc).

\section{Anthracnose resistance QTL mapping}

Data on anthracnose resistance scores (Książkiewicz et al. 2017) and an updated linkage map from this study were used to re-draw QTL loci. As the study was aiming to develop PCRbased markers for preselection of germplasm carrying published candidate anthracnose resistance loci, we did not perform new phenotyping of RIL population. Thus, we used average values (trait antr_avg) across two years of anthracnose resistance screening in Perth, Australia, which encompassed three independent experiments per year (trait antr04, $n=151$; trait antr05, $n=191$ ) (Książkiewicz et al. 2017; Phan et al. 2007). Interval mapping (van Ooijen 1992) was performed using MapQTL 6 (Kyazma, Wageningen, Nederlands) (Supplementary Table S3). The LOD threshold of 3.5 was used for QTL determination. QTLs were located at positions with the highest LOD values. Composite interval mapping was performed in Windows QTL Cartographer V2.5 (North Carolina State University, Raleigh, USA) using 20 background control markers window size $10 \mathrm{cM}$ and walk speed $0.5 \mathrm{cM}$ to exactly follow the approach used during the reference study (Książkiewicz et al. 2017). Linkage groups and LOD graphs were drawn in MapChart (Voorrips 2002). Marker sequences developed in this study (LC416306-LC416345) were aligned to the L. albus genome assembly (Hufnagel et al. 2020), using custom BLAST database ( $e$-value $1 \mathrm{e}-20,1$ best hit) implemented in Geneious, to find genome regions collinear to QTL 
Table 1 List of developed markers for antr04_1/antr05_1 QTL, with primer sequences, PCR amplification temperature, validated enzymes, and restriction product sizes

\begin{tabular}{|c|c|c|c|c|c|}
\hline Name & Primers & $\mathrm{PCR}{ }^{\circ} \mathrm{C}$ & Enzyme & $\begin{array}{l}\text { Products Kiev Mutant } \\
\text { (length in bp) }\end{array}$ & $\begin{array}{l}\text { Products P27174 } \\
\text { (length in bp) }\end{array}$ \\
\hline WANR1F ${ }^{\mathrm{a}}$ & GAGTCACTTAGAAATAAAGG & 51 & - & $\sim 190$ & $\sim 180, \sim 220$ \\
\hline WANR1R & GATCCATGAAGATACATTG & & & & \\
\hline TP23903F & CAGCAATATTGAGAGCAACCAA & 56 & BseGI & 49,15 & 64 \\
\hline TP23903R & TGTATTATATGGCTTTGATTGTGTC & & & & \\
\hline TP229924F & CACACTTGCACTTAATGGTTATATGCACG & 60 & $R s a \mathrm{I}$ & 54,30 & 84 \\
\hline TP229924R & AAAATCCCCACCCAAATGGC & & & & \\
\hline TP272531F & TCATTGTCATAGATAATTGCAGCT & 60 & $H p y \mathrm{~F} 3 \mathrm{I}$ & 112,49 & 161 \\
\hline TP272531R & GAGCCACTTGATGCATGTACA & & & & \\
\hline TP222136F & CTTCACCCAGTCTCTATCTGCAC & 63 & CviKI-1 & $168,27,15$ & 183,27 \\
\hline TP222136R & AATGAGCATGCTTAATCTTGTTGCA & & & & \\
\hline TP47110F & TTAGCTGGTTTAATGTGGTGGCACTCA & 60 & HpyF3I & 42,24 & 66 \\
\hline TP47110R & AAAGAGCAAACCAAGCCTATCT & & & & \\
\hline TP446132F & CAAAAGCAGGTTGATGTGAATTCT & 60 & TaaI & 240 & 130,110 \\
\hline TP446132R & CAGCTGCTGGTTTTCGTTGAAA & & & & \\
\hline TP291372F & GCGAATGCTTTCTCTTGTTCTTG & 60 & MunI & 54,51 & 105 \\
\hline TP291372R & ACATACCCACTGAGATCAAGCA & & & & \\
\hline TP237794F & GCTCATAACTTAGCTCCTTTTCCCT & 64 & MseI & 39,27 & 66 \\
\hline TP237794R & AAATGAGGCACCTACATCAAGAACTTA & & & & \\
\hline TP38227F & AATGAAACGAACTCTTCTTGCAGC & 60 & MwoI & 76,29 & 105 \\
\hline TP38227R & TGGCTTTCACTTCTCAGCTATTTG & & & & \\
\hline TP88533F & CTGAACCCAGCATCAGTGTT & 60 & NlaIII & 99 & 55,44 \\
\hline TP88533R & ATCAAATAGCTGAGAAGTGAAAGCC & & & & \\
\hline
\end{tabular}

${ }^{\mathrm{a}}$ As previously published (Yang et al. 2010)

loci conferring anthracnose resistance. Genes localized in these regions were screened for the presence of typical domains using the Disease Resistance Analysis and Gene Orthology
(DRAGO 2) tool at the Plant Resistance Genes database (PRGdb) (Osuna-Cruz et al. 2018).

Table 2 List of developed markers for antr04 2/antr05 2 QTL, with primer sequences, PCR amplification temperature, validated enzymes, and restriction product sizes

\begin{tabular}{|c|c|c|c|c|c|}
\hline Name & Primers & $\begin{array}{l}\mathrm{PCR} \\
{ }^{\circ} \mathrm{C}\end{array}$ & Enzyme & $\begin{array}{l}\text { Products } \\
\text { Kiev Mutant (length in bp) }\end{array}$ & $\begin{array}{l}\text { Products } \\
\text { P27174 (length in bp) }\end{array}$ \\
\hline WANR3F $^{\mathrm{a}}$ & TTAAGCCAAGATTCTACTTAG & 51 & - & 160 & 141 \\
\hline WANR3R & ACTAGCACTTGTGTGTGTGTGTG & & & & \\
\hline TP149038F & CCTCAGCATGTCCAAGTCGAA & 60 & MunI & 100 & 65,35 \\
\hline TP149038R & TTCACTTTGCCAGCCTTTTCTT & & & & \\
\hline $\mathrm{TP} 416765 \mathrm{~F}$ & CACACTGGTCATGCTTCCTTCAA & 60 & BseDI & 54,38 & 92 \\
\hline TP416765R & GCGGCTGGATGTGGAGGA & & & & \\
\hline TP3712F & TCAACAACACAAATCAATGCAACA & 60 & $C v i \mathrm{KI}-1$ & 171,29 & $123,48,29$ \\
\hline TP3712R & CCGAAGCAGAACCACCAAAAT & & & & \\
\hline TP364001F & CCGAAGCAGAACCACCAAAAT & 56 & $C v i \mathrm{KI}-1$ & $116,48,29$ & 164,29 \\
\hline TP364001R & CACAAATCAATGCAACAATCACA & & & & \\
\hline TP37593F & CAGCAGCACCCATTTGGAAAG & 56 & MboII & 68,51 & 119 \\
\hline TP37593R & AGTAACGTCATCCACTATAGAAAA & & & & \\
\hline TP26007F & TCTGGTTCACCGGTTTATCTCCGACTGAC & 60 & NlaIII & 107 & 75,32 \\
\hline TP26007R & GGTAGCCACTGATTTCGGTTC & & & & \\
\hline TP106254F & GTCCCGAAGTATATTTATCAGAAGG & 56 & TasI & $52,50,16$ & 68,50 \\
\hline TP106254R & GGGATCACTCATCTATCCAAT & & & & \\
\hline TP338761F & TCCTTGAGAGAATCCAAGCTGC & 60 & SchI & 83,28 & 64,47 \\
\hline TP338761R & CTACAATGCACACGAGATTGCC & & & & \\
\hline TP440375F & TACCCACATTTATGTAAACCTTTGACTTT & 60 & $\operatorname{DraI}$ & 70,29 & 99 \\
\hline TP440375R & AAAAGGCTGAGTTAGACACACAC & & & & \\
\hline TP93026F & CAGTGGTTGCTGGCTCTTCCA & 56 & NlaIII & 33,23 & 56 \\
\hline TP93026R & CGATCATCCACGCCACTATGC & & & & \\
\hline
\end{tabular}

${ }^{a}$ As previously published (Yang et al. 2010) 


\section{Assay of marker polymorphism in diversified germplasm}

The set of 107 L. albus lines derived from the European Lupin Gene Resources Database maintained by Poznań Plant Breeders Ltd. station located in Wiatrowo was used: 51 primitive populations, 30 landraces, 16 cultivars, 7 cross derivatives, and 3 mutants. These lines originated from 22 countries (Supplementary Table S4). Markers were scored using the same methods as those applied for the RIL population. For binary data similarity analysis, Kiev Mutant-like scores were assigned as 0, P27174-like scores as 1, heterozygotes as 1, and additional alleles as 0. Simple matching (Sokal and Michener 1958) and Rogers-Tanimoto (Rogers and Tanimoto 1960) coefficients were calculated using a Binary Similarity Calculator http://www.minerazzi.com/tools/similarity/binary-similaritycalculator.php.

\section{Genomic selection model}

A genomic selection model was built to investigate the possibility of predicting anthracnose resistance scores derived from the RIL population. The set of GBS-derived single nucleotide polymorphism (SNP) markers, after validation via chi-square test, was filtered for growing levels of missing rate per marker $(10 \%, 20 \%, 30 \%, 40 \%$, and $50 \%)$, resulting in five different genotype matrices with a growing number of markers (631, $1859,2430,2833$, and 3230, respectively). Following Nazzicari et al. (2016), the remaining missing data-points were imputed using Random Forest Imputation by the R package missForest (Stekhoven and Bühlmann 2012) with parameters ntree $=100$, maxiter $=10$, and parallelize $=$ variables. The target traits were the two sets of anthracnose disease resistance scores issued from each year of evaluation (traits antr04 and antr05) and the average score across years (trait antr_avg).

For genome-wide predictions, we applied the ridge regression BLUP model (Searle et al. 2008), which displayed comparatively high predictive ability in prior studies on other legume species such as pea (Annicchiarico et al. 2017a), white lupin (Annicchiarico et al. 2019), and alfalfa (Annicchiarico et al. 2015). Ridge regression BLUP analysis was performed through the R software package rrBLUP (Endelman 2011), assessing the model predictive ability as Pearson's correlation between true and predicted scores. In particular, the mixed model:

$y=Z u+e$

with $y$ being the phenotypes, $Z$ being the genotype matrix, and $u$ a vector of random effects with variance $\sigma^{2}{ }_{u}$ was solved in a maximum likelihood (ML/REML) framework using the function "mixed.solve" from rrBLUP package. With this approach, the (equivalent in ML of the) ridge parameters is estimated via $\lambda=\sigma^{2} e_{e} / \sigma^{2}$ and thus it can be computed directly from the data without variance component estimation.

The model was trained in a tenfold cross-validation schema, and training was repeated 50 times for each trait and then averaged to ensure numerical stability, using the R package GROAN (Nazzicari and Biscarini 2017).

\section{Results}

\section{Twenty PCR-based markers were developed for two major anthracnose resistance QTLs}

The region from 0.00 to $4.74 \mathrm{cM}$ on the linkage group ALB02, which carried the antr04_1/antr05_1 anthracnose resistance QTL (explaining approximately $25-28 \%$ of phenotypic variance) (Książkiewicz et al. 2017; Phan et al. 2007) and contained 22 sequence-defined markers developed by GBS, was selected. Perfectly matching transcriptome sequences were assigned for 14 markers (64\%) using available datasets (Książkiewicz et al. 2017; O'Rourke et al. 2013). Eleven GBS markers were selected for transformation to PCR-based markers (one directly and ten using complementary transcriptome sequences), based on the position on the linkage map and availability of affordably priced restriction enzymes. The summary of this transformation is included in Supplementary Table S5. Comparative mapping to L. albus transcriptome and L. angustifolius genome sequences (Hane et al. 2017) provided coordinates for intron/exon boundaries for ten markers. The list of L. albus transcriptome contigs anchored to GBS sequences is provided in Supplementary Table S6, whereas the coordinates of corresponding L. angustifolius genome regions are provided in Supplementary Table S7. The position of markers confirmed the highly conserved collinearity between the regions of L. albus linkage group ALB02 and L. angustifolius chromosome NLL-20. The WANR1 marker already implemented in marker-assisted selection of antr04_1/antr05_1 QTL in Australian breeding programs (Yang et al. 2010) was also included in the analysis. PCR amplicons were obtained for all primer pair combinations. Restriction enzyme cleavage of these amplicons yielded expected products for all markers except TP254603, which revealed additional unspecific amplification. The list of developed markers with primer sequences, PCR amplification temperature, validated enzymes, and restriction product sizes is given in Table 1.

A second region selected for marker development was that from 115.99 to $128.75 \mathrm{cM}$ on the linkage group ALB04, which carried antr04_2/antr05_2 anthracnose resistance QTL (explaining approximately $15-23 \%$ of 
phenotypic variance) (Książkiewicz et al. 2017; Phan et al. 2007) and included 23 GBS markers. Twelve GBS sequences were chosen for marker development (Supplementary Table S5). Alignment to L. albus transcriptome and $L$. angustifolius genome sequences provided matching sequences for ten and twelve GBS sequences, respectively, and provided novel evidence for collinearity between the regions of L. albus linkage group ALB04 and L. angustifolius chromosome NLL-02 (Supplementary Table S6 and S7). WANR3 marker used for molecular selection of antr04_2/antr05_2 allele in Australian breeding programs (Yang et al. 2010) was also included in the analysis. PCR amplicons were obtained for 11 primer pairs (85\%). Restriction enzyme cleavage confirmed the presence of expected polymorphic loci in all amplicons (Table 2).

\section{PCR-based markers refined mapping resolution at both QTL loci}

The segregation pattern of 22 markers in the white lupin RIL mapping population was resolved. Newly developed GBSderived and previously published simple sequence repeat (SSR)-derived PCR markers revealed high amplification stability, providing on average $98.4 \%$ (antr04_1/antr05_1) and 98.5\% (antr04_2/antr05_2) reads for the RIL population. Taking into consideration that GBS markers had on average $71.4 \%$ RIL data for antr04_1/antr05_1 and $74.4 \%$ for antr04_2/antr05_2, this approach improved segregation data by $37.8 \%$ and $32.4 \%$, respectively (Supplementary Table S 8 and S9). Thus, it contributed to linkage mapping refinement and increased map resolution as visualized by smaller blocks of co-segregating markers in both regions (Fig. 1). The order of markers was highly reproducible, as highlighted by low SD values of relative marker positions calculated for ten mapping runs: from 0.0 to 0.6 for antr04_1/antr05_1 and from 0.0 to 2.2 for antr04_2/antr05_2 loci (Supplementary Table S9). High fidelity of these markers was reflected by high LOD values of linkage to adjacent markers, ranging from 22.3 to 55.1 in antr04_1/antr05_1 and from 18.6 to 56.0 in antr04_2/ antr05 2 .

The updated linkage map was subjected to QTL mapping using phenotype observations from previous studies (Książkiewicz et al. 2017). The presence of two major anthracnose resistance QTLs in linkage groups ALB02 and ALB04, resolving about 45-50\% of observed phenotypic variance, was confirmed (Table 3, Fig. 1). Linkage map improvement contributed to higher LOD values compared to the earlier study (Książkiewicz et al. 2017), indicating strengthened statistical significance of QTL mapping results. LOD values for antr04_1/antr05_1 locus were 13.3 in this study vs 10.3 (the most recent linkage map) in interval mapping (MapQTL), and 32.8 vs 22.7 in composite interval mapping (WinQTL
Cartographer). The same result was observed for antr04_2/ antr05 2, yielding LOD values 5.4 vs 5.2 in interval mapping and $26.6 \mathrm{vs} 14.7$ in composite interval mapping. The position of the LOD peak for the major resistance QTL (antr04 1/ antr05 1) was almost identical for both experiments and methods, fitting within the range of $0.2 \mathrm{cM}$. The position of the LOD peak for the second QTL (antr04_2/antr05_2) covered the range of $6.2 \mathrm{cM}$.

\section{Three markers revealed applicability for Ethiopian allele selection}

Pearson correlation between the observed anthracnose resistance phenotype and marker genotype in the RIL population was in the range of $0.49-0.58$ for antr04_1/antr05_1 and 0.28-0.39 for antr04_2/antr05_2. The significance (both one-tailed and two-tailed probability) of the correlation coefficients, given the correlation values and the sample size (190 RILs with anthracnose resistance scores), was very high: $p$ values were $\sim 0.0$ for antr04_1/antr05_1 and below 0.00009 for antr04_2/antr05_2.

Significant linkage disequilibrium decay was observed in both anthracnose resistance QTL regions in a set of 107 white lupin core collection lines (Fig. 2, Supplementary Table S10). As the resistance allele originated from one mountainous region of Ethiopia (Adhikari et al. 2013; Raman et al. 2014), it is uncommon to have it in the germplasm which has not been crossed with any Ethiopian line. Therefore, we expected to have "susceptible" marker scores for all European, African, and Middle East lines except the Ethiopian parent P27174 (distribution ratio like 106 vs 1). Simple matching coefficients were calculated, to compare the marker and expected phenotype. These values ranged from 0.25 to 0.96 for antr04_1/ antr05_1 and 0.33-0.89 for antr04_2/antr05_2, indicating high similarity of marker pattern and hypothetical possession of resistant alleles.

We calculated values of the Rogers-Tanimoto (RT) coefficient, to address the putative applicability of markers in the selection of germplasm for further disease resistance assays. This coefficient is a variant of the simple matching coefficient that gives double weight to mismatching variables, thereby resulting more convenient for the analysis of false-positive scores. We found high RT values, with maxima of 0.93 in antr04_1/antr05_1 and 0.80 in antr04_2/antr05_2. This was a considerable improvement over the previous markers, highlighted by RT values as low as 0.59 for antr04 1/ antr05 1 (WANR1) and 0.49 for antr04_2/antr05_2 (WANR3). Two newly developed markers for antr04_1/ antr05 1 (TP222136 and TP47110) and one for antr04_2/ antr05 2 (TP338761) were revealed to be applicable for selection of Ethiopian alleles with $>90 \%$ confidence (Table 4, Supplementary Figure S1). 


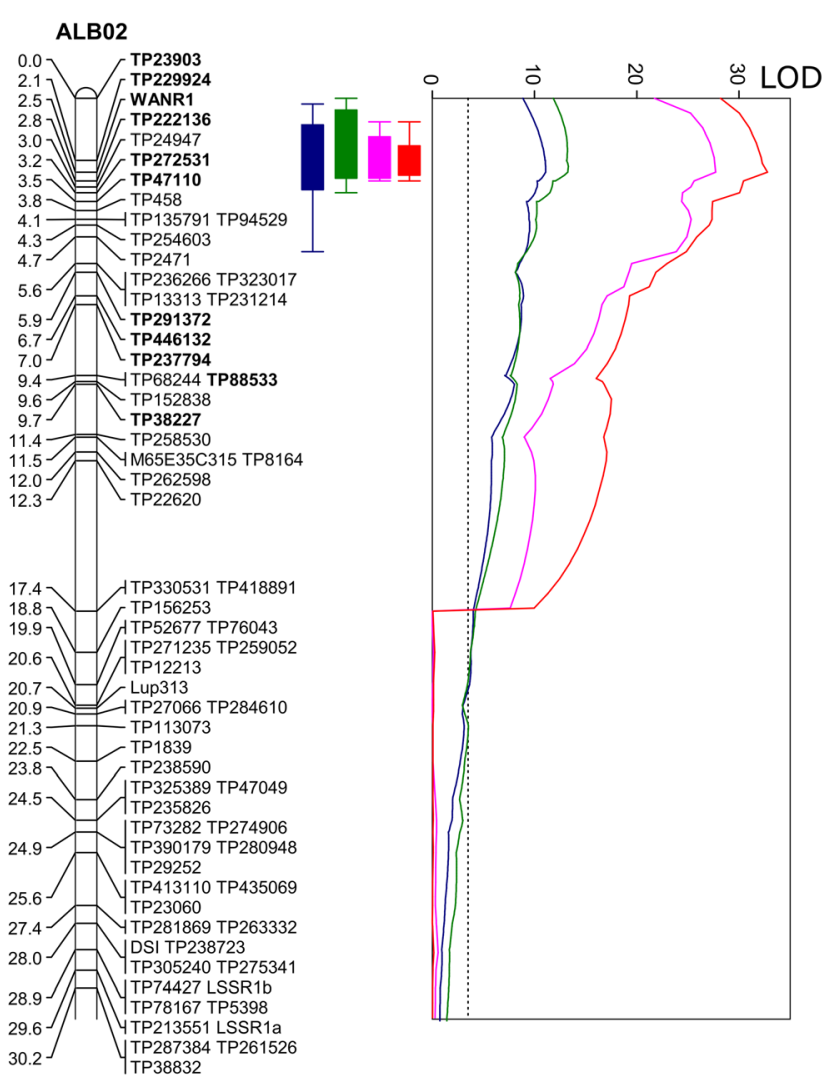

ALB04
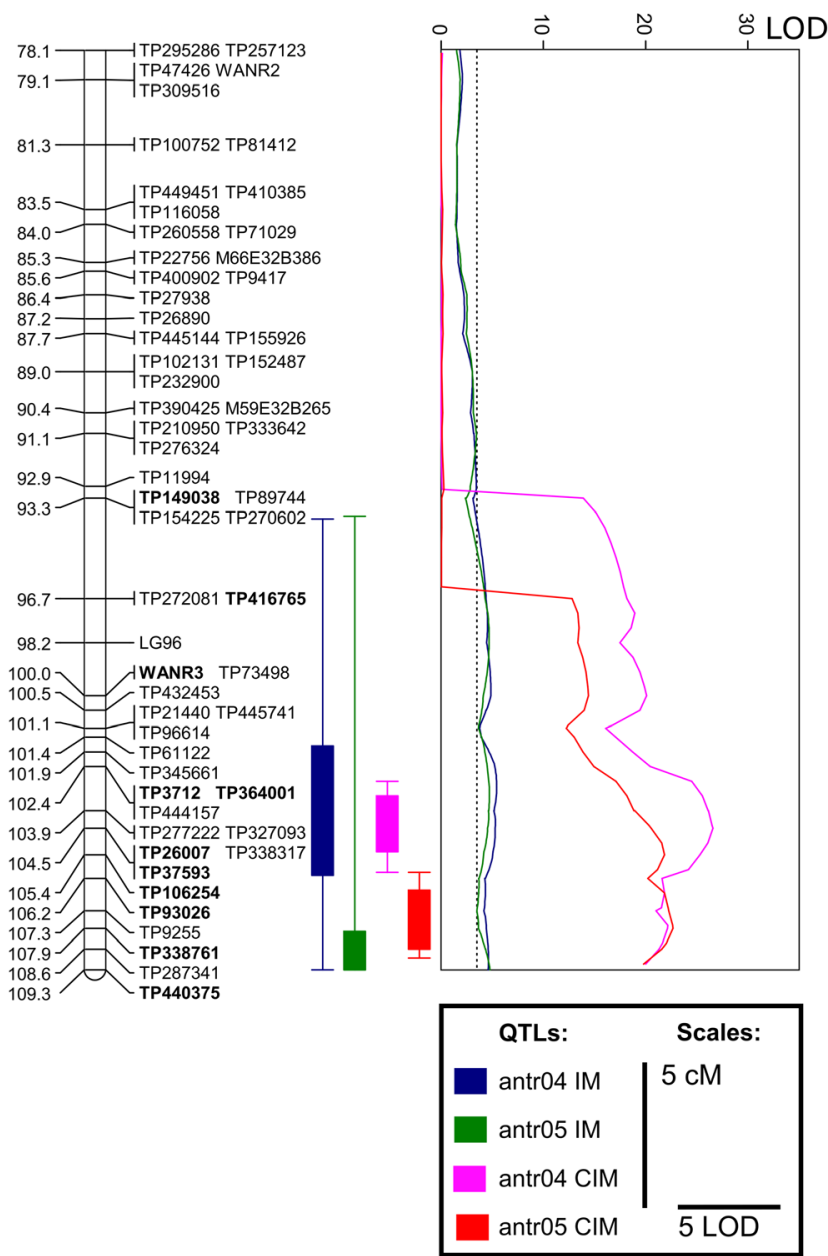

included into PCR-based assay are bold faced. Colors correspond to QTL assays: interval mapping, IM, blue (antr04, the first year) and green (antr05, the second year); composite interval mapping, CIM, pink (antr04) and red (antr05). Linkage groups and LOD graphs are drawn to scale

linkage map and genome assembly in both QTLs. The list of genes identified in the regions of white lupin genome carrying anthracnose resistance loci is provided in the Supplementary Table S12. Several candidate genes were identified, namely Lalb_Chr02g0142231 (putative protein ENHANCED DISEASE RESISTANCE 2, EDR2), Lalb_Chr02g0141611

Table 3 Two major anthracnose resistance QTLs detected in a recombinant inbred line population of white lupin. PVE - proportion of phenotypic variance explained by QTL

\begin{tabular}{|c|c|c|c|c|c|c|c|c|c|}
\hline \multirow[t]{2}{*}{ QTL } & \multirow[t]{2}{*}{ LG } & \multicolumn{4}{|c|}{$\begin{array}{l}\text { Interval mapping } \\
\text { (MapQTL6) }\end{array}$} & \multicolumn{4}{|c|}{$\begin{array}{l}\text { Composite interval mapping } \\
\text { (WinQTL Cartographer) }\end{array}$} \\
\hline & & Locus $(\mathrm{cM})$ & LOD & Additive effect & PVE & Locus (cM) & LOD & Additive effect & PVE \\
\hline antr04_1 & ALB02 & 2.5 & 11.1 & -0.58 & 28.8 & 2.5 & 27.7 & -0.61 & 25.1 \\
\hline antr05_1 & ALB02 & 2.3 & 13.3 & -0.46 & 27.7 & 2.5 & 32.8 & -0.45 & 23.9 \\
\hline antr04_2 & ALB04 & 103.1 & 5.4 & -0.42 & 15.3 & 104.5 & 26.6 & -0.54 & 23.1 \\
\hline antr05_2 & ALB04 & 109.3 & 4.8 & -0.28 & 11.0 & 107.9 & 22.7 & -0.34 & 14.6 \\
\hline
\end{tabular}


Fig. 2 Linkage disequilibrium pattern observed for PCR-based markers from ALB02 (a) and ALB04 (b) linkage groups. The set of 107 white lupin lines originating from 22 countries ( 81 primitive populations and landraces and 26 domesticated) was used to estimate $R^{2}$ values a

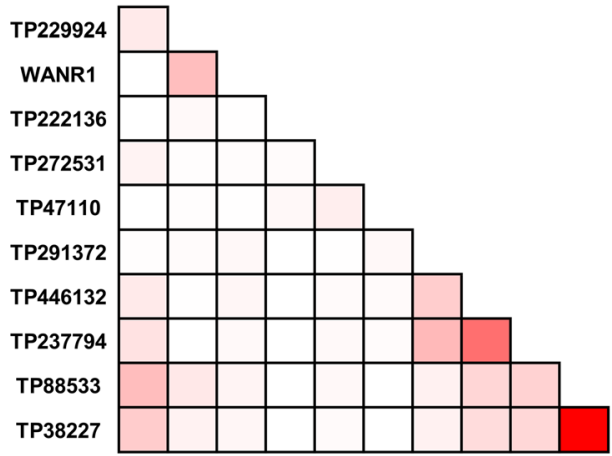

b

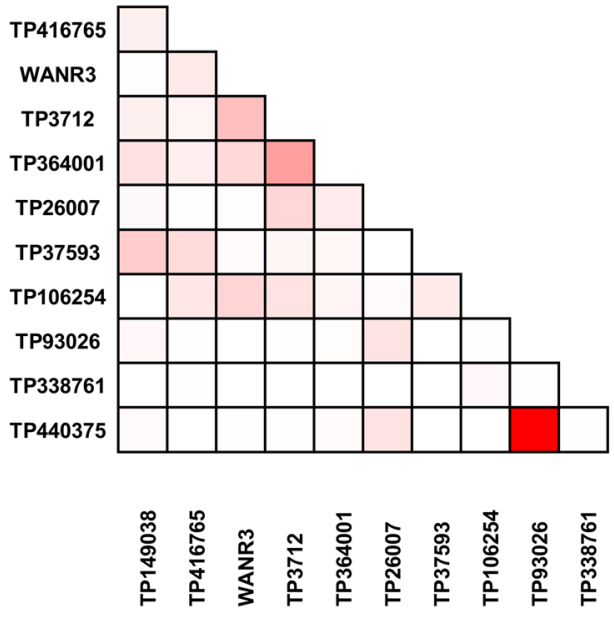

\begin{tabular}{l|l|l|l|l|l|l|l|l|l|l|}
$\mathbf{R}^{2}$ scale & 0.0 & 0.1 & 0.2 & 0.3 & 0.4 & 0.5 & 0.6 & 0.7 & 0.8 & 0.9 \\
\hline
\end{tabular}

(putative protein kinase RLK-Pelle-LRR-XI-1 family), and Lalb_Chr02g0141701 (putative transferase, protein kinase RLK-Pelle-LRR-II family) for the antr04_1/antr05_1 locus and Lalb_Chr04g0264801 (putative protein kinase RLKPelle-RLCK-IXb family) for the antr04_2/antr05_2 locus. Screening of coding sequences using the Plant Resistance Genes database revealed the presence of kinase, coiled-coil (CC), leucine-rich repeat (LRR), nucleotide binding site (NBS), Toll/interleukin-1 receptor (TIR), and transmembrane (TM) domains (Supplementary Table S13).

\section{Genomic selection displayed moderately high ability to predict anthracnose tolerance}

Average predictive abilities of whole-genome regression models for the three traits (antr04, antr05, and antr_avg) are reported in Fig. 3. The best predictive ability values were found for antr05 and antr_avg, which showed similar values. The trait antr04 displayed lower predictive ability values, probably because of the lower number of available samples (only 151, compared to 191 available for antr05). When one of the two scores was missing, the average resistance score (antr_avg) was based only on data of the other score (Książkiewicz et al. 2017). The effect of filtering on maximum allowed missing rate for markers exhibited a clear pattern of better predictions with low missing rates. The absolute best performances were achieved for $10 \%$ maximum missing rate (implying 631 markers), which resulted in predictive abilities of $0.491,0.558$, and 0.557 for antr04, antr05, and antr_avg, respectively. This can be linked to the effective total missing rate pre-imputation. For the filtering thresholds of $10 \%, 20 \%$, $30 \%, 40 \%$, and $50 \%$, the utilized data set resulted in missing rates of $1.8 \%, 4.8 \%, 7.2 \%, 9.8 \%$, and $13.2 \%$, respectively.

\section{Discussion}

\section{Ethiopian sources of anthracnose resistance arise from non-domesticated primitive lines}

Following the anthracnose appearance in 1996, all L. albus lines from the Lupin Genetic Collection at the Department of Agriculture and Food Western Australia were phenotyped for anthracnose resistance. From more than 8 hundred accessions tested, originating from 21 countries and four continents, all breeding materials (416 lines) and $97 \%$ of primitive populations and landraces were found to be very susceptible to anthracnose (Adhikari et al. 2009). Despite testing of a large seed collection, a significant and reproducible level of resistance was found only in several Ethiopian landrace accessions, P27172, P27174, P27175, P27178, P28512, P28523, and P28538 (Adhikari et al. 2009). The three most resistant lines (P27172, P27174, P27178) were collected in one district, Debre Markos, at altitudes around $2000 \mathrm{~m}$. Genotyping of 94 white lupin accessions with PCR-based SSR and microarraybased Diversity Array Technology markers revealed that Ethiopian accessions formed a separate clade, indicating their close genetic relation and distinctiveness from other germplasm (Raman et al. 2014). Assay based on the analysis of agronomical and phenological traits revealed relatively high similarity of Ethiopian white lupin germplasm grouped into several clusters showing significant genetic distance from the German accession used as an outgroup (Atnaf et al. 2015). Recent SSR-based screening of 212 Ethiopian white lupin landraces confirmed low population differentiation among four major white lupin collection areas in the country (Atnaf et al. 2017). These observations have substantial consequences for breeders, who shall apparently deal with the only genetic source of white lupin anthracnose resistance 
Table 4 Results of PCR marker validation: distance to QTL peak on the linkage map (cM), correlation values between anthracnose resistance phenotype and marker genotype in RIL population, and simple matching (SM) and Rogers-Tanimoto (RT) coefficient values, in lines of a white lupin core collection

\begin{tabular}{|c|c|c|c|c|c|}
\hline Name & Distance to QTL (cM) & $\begin{array}{l}\text { Correlation coefficient } \\
\text { for RIL population }\end{array}$ & $\begin{array}{l}\text { SM value for } \\
\text { germplasm collection }\end{array}$ & $\begin{array}{l}\text { RT value for } \\
\text { germplasm collection }\end{array}$ & $\begin{array}{l}\text { Applicability for } \\
\text { marker-assisted selection }\end{array}$ \\
\hline ТР23903 & -2.50 & 0.55 & 0.54 & 0.37 & - \\
\hline ТР229924 & -0.36 & 0.58 & 0.78 & 0.63 & - \\
\hline WANR1 & -0.02 & 0.58 & 0.74 & 0.59 & - \\
\hline ТР222136 & +0.33 & 0.56 & 0.96 & 0.93 & + \\
\hline ТР272531 & +0.67 & 0.55 & 0.83 & 0.71 & - \\
\hline ТР47110 & +1.02 & 0.53 & 0.96 & 0.93 & + \\
\hline ТР291372 & +3.39 & 0.49 & 0.34 & 0.20 & - \\
\hline ТР446132 & +4.19 & 0.53 & 0.25 & 0.14 & - \\
\hline ТР237794 & +4.45 & 0.51 & 0.25 & 0.14 & - \\
\hline ТР88533 & +6.96 & 0.48 & 0.52 & 0.35 & - \\
\hline ТР38227 & +7.20 & 0.51 & 0.49 & 0.32 & - \\
\hline ТP149038 & -12.89 & 0.28 & 0.53 & 0.36 & - \\
\hline ТР416765 & -9.50 & 0.36 & 0.56 & 0.39 & - \\
\hline WANR3 & -6.20 & 0.36 & 0.65 & 0.49 & - \\
\hline TP3712 & -3.83 & 0.38 & 0.58 & 0.41 & - \\
\hline TP364001 & -3.83 & 0.39 & 0.33 & 0.20 & - \\
\hline ТР37593 & -1.68 & 0.38 & 0.65 & 0.49 & - \\
\hline ТР26007 & -1.68 & 0.38 & 0.64 & 0.48 & - \\
\hline TP106254 & -0.84 & 0.36 & 0.65 & 0.49 & - \\
\hline ТР93026 & 0.00 & 0.35 & 0.64 & 0.48 & - \\
\hline TP338761 & +1.89 & 0.34 & 0.89 & 0.80 & + \\
\hline ТР440375 & +3.10 & 0.37 & 0.66 & 0.50 & - \\
\hline
\end{tabular}

worldwide, buried in landrace germplasm locally adapted to mountain Ethiopian climatic conditions and carrying numerous undesired traits such as high alkaloid content, late flowering, vernalization responsiveness, and low yield (Adhikari et al. 2009; Kroc et al. 2017; Lin et al. 2009; Phan et al. 2007). Indeed, Ethiopian germplasm displayed poor adaptation to European environments in a multi-environment evaluation (Annicchiarico et al. 2010). The line P27174 as a well-recognized anthracnose resistance donor was crossed with the very susceptible Kiev Mutant to generate an advanced recombinant inbreed line population for mapping studies (Phan et al. 2007). Anthracnose phenotyping in independent experiments, followed by marker development and linkage mapping, provided clear evidence for a quantitative pattern of resistance, indicating the involvement of several unrelated heritable factors (Adhikari et al. 2009; Książkiewicz et al. 2017; Phan et al. 2007; Vipin et al. 2013; Yang et al. 2010). White lupin breeding for anthracnose resistance has been hampered so far by a lack of molecular markers to track resistant alleles. There were only few markers linked to white lupin agronomic traits published hitherto, one for the low-alkaloid pauper locus and three for two anthracnose resistance loci, and the usefulness of these markers was limited

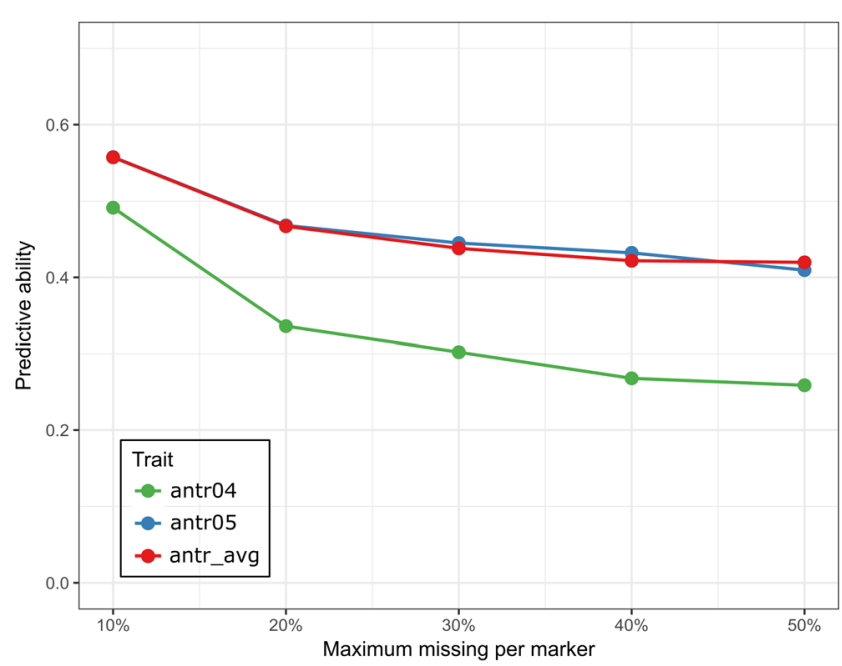

Fig. 3 Predictive ability of ridge regression BLUP models as measured by Pearson's correlation between true and predicted values as a function of the maximum allowed missing rate for single SNP markers, for three anthracnose disease resistance scores from the first year (antr04), the second year (antr05), and mean from both years (antr_avg). Values are derived through 10 -fold cross-validations and averaged over 50 repetitions 
by non-negligible ratios of false-positive scores in diversified germplasm (Lin et al. 2009; Yang et al. 2010). White lupin anthracnose resistance donors are late flowering. Both traits are under polygenic control, which makes breeding attempts much more challenging than in the narrow-leafed lupin. Combining anthracnose resistance with early flowering by traditional breeding has been fairly unsuccessful over two decades, and the hypothesis of a linkage between these traits was put forward (Adhikari et al. 2009). This hypothesis was recently confirmed, as the major anthracnose resistance QTL (antr04_1/antr05_1) and one of the major early flowering QTLs (nonv05_1/nonv15_1/nonv16_1) were located in the same linkage group (Książkiewicz et al. 2017; Rychel et al. 2019). Moreover, one of the few minor early flowering QTLs was found just several centimorgans away from the antr04_1/ antr05_1 locus.

\section{Availability of marker-assisted selection for lupin breeders}

The white lupin PCR-based marker toolbox contains several markers developed for candidate genes (FLOWERING LOCUS T, GIGANTEA, SEPALLATA, and FRIGIDA) conferring QTLs of flowering time (Rychel et al. 2019), a pair of markers tagging low-alkaloid pauper locus, including one anchored in a candidate gene (LaAT), and six markers for anthracnose resistance, including three developed in this study (Lin et al. 2009; Rychel and Książkiewicz 2019; Rychel et al. 2019; Yang et al. 2010).

Unlike white lupin, narrow-leafed lupin exhibited high effectiveness of anthracnose resistance breeding, leading to the development of a large collection of resistant germplasm (Fischer et al. 2015; Yang et al. 2012). Three factors contributed to this achievement: (i) the monogenic inheritance of the resistance, (ii) the presence of resistance alleles in germplasm that had already been subjected to selection for regional adaptation, and (iii) the development and successful implementation of truly selective markers into breeding programs. The resistance to anthracnose in narrow-leafed lupin is controlled by several single dominant genes that were discovered in different germplasm resources, namely Lanrl in cv. Tanjil, AnMan in cv. Mandelup, and LanrBo in the breeding line Bo7212 (Fischer et al. 2015; Yang et al. 2004; Yang et al. 2008). Interestingly, none of these loci were localized in genome regions collinear to the white lupin regions carrying QTLs for anthracnose resistance (Książkiewicz et al. 2017). Nevertheless, annotation of white lupin genome regions carrying two major anthracnose resistance QTLs revealed the presence of protein domains which are typical for disease resistance genes (Bent 1996; Dangl and Jones 2001; Jones 2001). Moreover, a homolog of the EDR2 gene conferring Arabidopsis thaliana resistance to biotrophic powdery mildew pathogen Erysiphe cichoracearum (Tang et al. 2005) was identified.

Narrow-leafed lupin breeding was also facilitated by the development of sequence-defined SSR-derived markers linked to key agronomic traits. These include soft seediness (Li et al. 2012a), reduced pod shattering (Boersma et al. 2007b; Boersma et al. 2009; Li et al. 2010; Li et al. 2012b), low alkaloid profile ( $\mathrm{Li}$ et al. 2011), early flowering (Boersma et al. 2007a; Nelson et al. 2017), and resistance to various fungal diseases, including anthracnose (Yang et al. 2004; Yang et al. 2008; You et al. 2005), Phomopsis stem blight (Yang et al. 2002), and lupin rust (Sweetingham et al. 2005). These markers, except those for lupin rust, were subsequently implemented in Australian breeding programs. The development of low-cost high-throughput sequencing methods opened new possibilities for molecular genetics. Mass sequencing has been exploited in narrow-leafed lupin, to provide several markers linked to anthracnose and Phomopsis stem blight resistance genes. Some of these SNPs were revealed to have a lower recombination rate between the particular trait and marker loci than the previously developed SSRbased markers, and were implemented into breeding practice (Książkiewicz et al. 2020; Książkiewicz and Yang 2020; Yang et al. 2015a; Yang et al. 2015b; Yang et al. 2013a; Yang et al. 2013b; Zhou et al. 2018). All of these molecular resources have greatly contributed to the improvement of narrow-leafed lupin as a crop.

Marker-assisted selection in lupin breeding in Europe is currently at an initial stage, contrary to Australia, where it has been commenced for more than 15 years, targeting around 20,000 plants annually (Książkiewicz and Yang 2020; Yang and Buirchell 2008). Various techniques for polymorphism detection were implemented in the Australian breeding program, including 96-well polyacrylamide denaturing gel electrophoresis, CAPS/dCAPS, single-stranded conformation polymorphisms, high-resolution melting, and highthroughput allele-specific nanofluidic array (Boersma et al. 2009; Li et al. 2012b; Yang et al. 2015a; Yang et al. 2015b; Yang et al. 2002; Yang et al. 2013a; Yang et al. 2013b; Zhou et al. 2018). In this study, CAPS/dCAPS markers were developed, which are preferred in small-scale experiments (Shavrukov 2016). Moreover, other markers for white lupin agronomic traits are also based on PCR and electrophoresis (Książkiewicz et al. 2017; Lin et al. 2009; Rychel and Książkiewicz 2019; Rychel et al. 2019; Yang et al. 2010). However, such markers are relatively expensive per data point (about 1-1.5 USD per sample) and have limited capacity. As sequences of developed markers have been publicly released (see accession numbers LC416306-LC416345), selected SNPs can be transformed to the other system allowing the high-throughput approach. Popular medium-scale systems include PCR with TaqMan probes, Kompetitive Allele Specific PCR (KASP) and RNase H2 enzyme-based amplification 
(rhAmp) (Broccanello et al. 2018). These methods are considerably cheaper than CAPS and dCAPS (0.12-0.41 USD per sample), provided that the number of analyzed samples corresponds to the number of reactions supported by the assay mix (min. 2-10 thousand) (Ayalew et al. 2019).

\section{Genomic selection can assist marker-assisted selec- tion of anthracnose resistance}

In this study, QTL mapping was performed to investigate the association of the resistance score to specific parts of the genome. A valid alternative analysis was genome-wide association mapping (GWAS), which can be used to score the association between thousands of SNP markers and the desired trait. Thus, GWAS was recently exploited in L. angustifolius, highlighting novel candidate genes for phenology, growth, and yield traits (Plewiński et al. 2020). However, it was shown that GWAS can lead to false associations if the trait of interest is present in a very small proportion $(<5 \%)$ of the population (Sonah et al. 2015). QTL mapping does not present such a limitation and was, therefore, preferred for the trait in the test RIL population.

An additional aim of this study was investigating the ability of a whole-genome genomic regression approach to predict anthracnose disease resistance scores. This modeling approach is typically used for marker-based selection of genetically complex traits (Heffner et al. 2010) relative to crop yield or crop quality, and did prove promising to improve the selection efficiency for crop yield and key quality traits of various legume species (Annicchiarico et al. 2015; Annicchiarico et al. 2017b; Biazzi et al. 2017; Jarquin et al. 2014). This unprecedented attempt to apply genomic selection for a legume crop trait controlled mainly by a few major QTLs revealed predictive ability values in the range of $0.50-0.55$. These values are comparable with those observed for several morphophysiological traits such as pod fertility, individual seed weight, plant height, leaf size, and mainstem proportion of seeds and number of leaves in a pioneer study focusing on a world collection of white lupin landraces (Annicchiarico et al. 2020). Results from the same germplasm collection or other material indicated that onset of flowering (also under oligogenic control) is highly predictable genomically (Annicchiarico et al. 2020), whereas the predictive ability of white lupin grain yield was in the range of $0.40-0.51$. The current predictive ability values may justify the inclusion of this resistance trait in GBS-based genomic selection programs in which this trait is one of several target traits under selection, possibly combining the predicted values of the different target traits into a selection index. Our genome-wide predictions were obtained using trait-agnostic markers, leveraging the similitude of the selection candidate to a general "resistant genetic profile" to predict future resistance. Besides the possible practical interest of applying genomic selection for the resistance trait by the same operational tool used of other target traits (i.e., without adopting an additional markerbased tool specific for the trait), the whole-genome selection approach may also allow explaining some of the $\sim 50 \%$ phenotypic variance that was not explained by the two observed QTLs, thereby adding some of the unavoidable missing heritability relative to QTLs (Brachi et al. 2011; Manolio et al. 2009) to the measurable contribution of the genetic background. For example, GBS-based genomic selection may address the possible presence of a third QTL for resistance to anthracnose (antr04_3) whose effect, however, did not reach statistical significance in composite interval mapping (Książkiewicz et al. 2017).

We noted that a lower number of markers (631, at $10 \%$ missing rate) resulted in predictive abilities higher than those obtained with more markers (e.g., 3230 at 50\% missing rate). While this can be surprising at face value, it must be considered that the information provided by markers with more missing data is more noisy. In other terms, there is a tradeoff between accepting more information at the cost of that information being of lower quality.

Breeding white lupin for anthracnose resistance without molecular selection has been an arduous process, as the polygenic control of major traits implies low frequency of desired phenotypes in the progeny. Moreover, anthracnose testing is largely destructive for seed samples, because of the impact of the disease and the lack of full immunity. In the present study, two types of molecular tools were developed: markers to focus essentially on this trait by the PCR-based procedure, and genomic selection to enable future multi-trait selection based on trait-specific models for material genotyped by GBS. These tools could enable the selection of germplasm carrying candidate Ethiopian alleles of two major anthracnose resistance loci what would decrease the number of lines subjected to disease screening. Also, they could prove valuable for locating other putatively tolerant material in germplasm collection. It should be noted that white lupin anthracnose resistance assays were performed using the approach exploiting spreader plants inoculated by spray inoculation, to mimic naturally occurring anthracnose (Phan et al. 2007; Yang et al. 2010) and an isolate C. lupini isolate 96A4 (IMI375715), classified into vegetative compatibility group 2 (Yang and Sweetingham 1998). Other methods, such as direct spraying of plants with spore suspension, inoculation of seeds before sowing, or injection of spores using a hypodermic needle to cotyledons or stems, were also used in lupin studies (Weimer 1952). Moreover, the Kiev Mutant $\times$ P27174 mapping population was phenotyped for resistance to anthracnose in Australia in wintertime, which is characterized by relatively low daily temperatures compared to those occurring in European regions where lupins are cultivated as a spring-sown crop. As the pathogenicity of C. lupini depends on the temperature pattern during infections and the strain of the pathogen (Dubrulle et al. 2020; Thomas 
et al. 2008), candidate lines selected by molecular markers should be subjected to disease resistance screening in local environment using domestic isolates.

Acknowledgments We thank the Department of Agriculture and Food of Western Australia (Perth, Australia) for the seeds of Kiev Mutant $\times$ P27174 mapping population. We also thank the Poznan Plant Breeding Ltd. station located in Wiatrowo for the seeds of white lupin lines for marker genotyping assay.

Author contributions SR-B isolated DNA from the RIL population and germplasm collection, optimized the PCR protocol for all markers, and resolved their segregation patterns by PCR, restriction enzyme cleavage, and electrophoresis. NN performed LD analysis and GBS genomic selection assay. PP and BW contributed to plant sampling and DNA isolation. PA participated in the concept of the study and manuscript drafting. MK performed in silico analysis of sequence data, designed PCR markers based on GBS data, performed linkage and QTL mapping, analyzed marker validation, and drafted the manuscript. All authors contributed to the manuscript preparation in relevant sections.

Funding European Community's Seventh Framework Programme LEGATO project (FP7-613551) and Polish Ministry of Science and Higher Education financial resources for research 2014-2017.

Data availability All data generated in this study are included in this published article and its supplementary information files and in the DNA Data Bank of Japan (LC416306-LC416345).

\section{Compliance with ethical standards}

This article does not contain any studies with human participants or animals performed by any of the authors.

Conflict of interest The authors declare that they have no conflict of interest.

Abbreviations ALB02, L. albus linkage group and chromosome; ALB04, L. albus linkage group and chromosome; AnMan, Anthracnose resistance gene present in $L$. angustifolius cultivar Mandelup; antr04 1, Anthracnose resistance locus present in L. albus linkage group ALB02; antr04_2, Anthracnose resistance locus present in L. albus linkage group ALB04; antr05 1, Anthracnose resistance locus present in L. albus linkage group ALB02; antr05_2, Anthracnose resistance locus present in L. albus linkage group ALB04; BLAST, Basic Local Alignment Search Tool; CC, Coiled-coil domain; EDR2, ENHANCED DISEASE RESISTANCE 2; GBS, Genotyping by sequencing; GWAS, Genomewide association mapping; KASP, Kompetitive Allele Specific PCR; Lanrl, Anthracnose resistance gene present in L. angustifolius cultivars Tanjil and Wonga; LanrBo, Anthracnose resistance gene present in L. angustifolius breeding line Bo7212; LOD, Logarithm of the odds (used to estimate power of marker linkage); LRR, Leucine-rich repeat; NBS, Nucleotide binding site; NLL-02, L. angustifolius linkage group and chromosome; NLL-20, L. angustifolius linkage group and chromosome; P27174, Anthracnose-resistant L. albus primitive landrace from Ethiopia; PVE, proportion of phenotypic variance explained by QTL; QTL, Quantitative trait locus; rhAmp, RNase H2 enzyme-based amplification; RIL, Recombinant inbred line; SNP, Single nucleotide polymorphism; SSR, Simple sequence repeat; STS, Sequence tagged site; TIR, Toll/interleukin-1 receptor; TM, Transmembrane domain; WANR1, Marker linked with anthracnose resistance locus in L. albus linkage group ALB02; WANR3, Marker linked with anthracnose resistance locus in L. albus linkage group ALB04
Open Access This article is licensed under a Creative Commons Attribution 4.0 International License, which permits use, sharing, adaptation, distribution and reproduction in any medium or format, as long as you give appropriate credit to the original author(s) and the source, provide a link to the Creative Commons licence, and indicate if changes were made. The images or other third party material in this article are included in the article's Creative Commons licence, unless indicated otherwise in a credit line to the material. If material is not included in the article's Creative Commons licence and your intended use is not permitted by statutory regulation or exceeds the permitted use, you will need to obtain permission directly from the copyright holder. To view a copy of this licence, visit http://creativecommons.org/licenses/by/4.0/.

\section{References}

Adhikari KN, Buirchell BJ, Thomas GJ, Sweetingham MW, Yang H (2009) Identification of anthracnose resistance in Lupinus albus L. and its transfer from landraces to modern cultivars. Crop Pasture Sci 60:472-479. https://doi.org/10.1071/CP08092

Adhikari KN, Thomas G, Diepeveen D, Trethowan R (2013) Overcoming the barriers of combining early flowering and anthracnose resistance in white lupin (Lupinus albus L.) for the Northern Agricultural Region of Western Australia. Crop Pasture Sci 64:914 921. https://doi.org/10.1071/CP13249

Altschul SF, Gish W, Miller W, Myers EW, Lipman DJ (1990) Basic local alignment search tool. J Mol Biol 215:403-410. https://doi. org/10.1016/S0022-2836(05)80360-2

Annicchiarico P, Harzic N, Carroni AM (2010) Adaptation, diversity, and exploitation of global white lupin (Lupinus albus L.) landrace genetic resources. Field Crop Res 119:114-124. https://doi.org/10. 1016/j.fcr.2010.06.022

Annicchiarico P, Manunza P, Arnoldi A, Boschin G (2014) Quality of Lupinus albus L. (white lupin) seed: extent of genotypic and environmental effects. J Agric Food Chem 62:6539-6545. https://doi. org/10.1021/jf405615k

Annicchiarico P, Nazzicari N, Li X, Wei Y, Pecetti L, Brummer EC (2015) Accuracy of genomic selection for alfalfa biomass yield in different reference populations. BMC Genomics 16:1020. https:// doi.org/10.1186/s12864-015-2212-y

Annicchiarico P, Nazzicari N, Pecetti L, Romani M, Ferrari B, Wei Y, Brummer EC (2017a) GBS-based genomic selection for pea grain yield under severe terminal drought. The Plant Genome 10 doi: https://doi.org/10.3835/plantgenome2016.07.0072

Annicchiarico P, Nazzicari N, Wei Y, Pecetti L, Brummer EC (2017b) Genotyping-by-sequencing and its exploitation for forage and coolseason grain legume breeding. Front Plant Sci 8:679. https://doi.org/ 10.3389/fpls.2017.00679

Annicchiarico P, Nazzicari N, Ferrari B, Harzic N, Carroni AM, Romani M, Pecetti L (2019) Genomic prediction of grain yield in contrasting environments for white lupin genetic resources. Mol Breed 39:142. https://doi.org/10.1007/s11032-019-1048-6

Annicchiarico P, Nazzicari N, Ferrari B (2020) Genetic and genomic resources in white lupin and the application of genomic selection. In: Singh KB, Kamphuis LG, Nelson MN (eds) The Lupin Genome. Springer International Publishing, Cham, pp 139-149. https://doi. org/10.1007/978-3-030-21270-4 10

Atnaf M, Tesfaye K, Dagne K, Wegary D (2015) Extent and pattern of genetic diversity in Ethiopian white lupin landraces for agronomical and phenological traits. Afr Crop Sci J 23:327-341. https://doi.org/ 10.4314/acsj.v23i4.3

Atnaf M, Yao N, Martina K, Dagne K, Wegary D, Tesfaye K (2017) Molecular genetic diversity and population structure of Ethiopian 
white lupin landraces: implications for breeding and conservation. PLoS One 12:e0188696. https://doi.org/10.1371/journal.pone. 0188696

Ayalew H, Tsang PW, Chu C, Wang J, Liu S, Chen C, Ma X-F (2019) Comparison of TaqMan, KASP and rhAmp SNP genotyping platforms in hexaploid wheat. PLoS One 14:e0217222-e0217222. https://doi.org/10.1371/journal.pone.0217222

Bent AF (1996) Plant disease resistance genes: function meets structure. Plant Cell 8:1757-1771. https://doi.org/10.1105/tpc.8.10.1757

Biazzi E, Nazzicari N, Pecetti L, Brummer EC, Palmonari A, Tava A, Annicchiarico P (2017) Genome-wide association mapping and genomic selection for alfalfa (Medicago sativa) forage quality traits. PLoS One 12:e0169234. https://doi.org/10.1371/journal.pone. 0169234

Boersma JG, Pallotta M, Li C, Buirchell BJ, Sivasithamparam K, Yang H (2005) Construction of a genetic linkage map using MFLP and identification of molecular markers linked to domestication genes in narrow-leafed lupin (Lupinus angustifolius L.). Cell Mol Biol Lett $10: 331-344$

Boersma JG, Buirchell BJ, Sivasithamparam K, Yang H (2007a) Development of a sequence-specific PCR marker linked to the $K u$ gene which removes the vernalization requirement in narrow-leafed lupin. Plant Breed 126:306-309. https://doi.org/10.1111/j.14390523.2007.01347.x

Boersma JG, Buirchell BJ, Sivasithamparam K, Yang H (2007b) Development of two sequence-specific PCR markers linked to the le gene that reduces pod shattering in narrow-leafed lupin (Lupinus angustifolius L.). Genet Mol Biol 30:623-629. https://doi.org/10. 1590/S1415-47572007000400020

Boersma JG, Nelson MN, Sivasithamparam K, Yang H (2009) Development of sequence-specific PCR markers linked to the Tardus gene that reduces pod shattering in narrow-leafed lupin (Lupinus angustifolius L.). Mol Breed 23:259-267. https://doi.org/ 10.1007/s11032-008-9230-2

Boschin G, D'Agostina A, Annicchiarico P, Arnoldi A (2007) The fatty acid composition of the oil from Lupinus albus cv. Luxe as affected by environmental and agricultural factors. Eur Food Res Technol 225:769-776. https://doi.org/10.1007/s00217-006-0480-0

Brachi B, Morris GP, Borevitz JO (2011) Genome-wide association studies in plants: the missing heritability is in the field. Genome Biol 12: 232. https://doi.org/10.1186/gb-2011-12-10-232

Broccanello C, Chiodi C, Funk A, McGrath JM, Panella L, Stevanato P (2018) Comparison of three PCR-based assays for SNP genotyping in plants. Plant Methods 14:28. https://doi.org/10.1186/s13007-0180295-6

Confortin TC et al (2017) Extraction and composition of extracts obtained from Lupinus albescens using supercritical carbon dioxide and compressed liquefied petroleum gas. J Supercrit Fluids 128:395-403. https://doi.org/10.1016/j.supflu.2017.06.006

Confortin TC, Todero I, Luft L, Soares JF, Mazutti MA, Zabot GL, Tres MV (2018) Importance of Lupinus albescens in agricultural and food-related areas: a review. 3 Biotech 8:448. https://doi.org/10. 1007/s13205-018-1474-x

Confortin TC et al (2019) Extracts from Lupinus albescens: antioxidant power and antifungal activity in vitro against phytopathogenic fungi. Environ Technol 40:1668-1675. https://doi.org/10.1080/09593330. 2018.1427800

Cowley R, Luckett DJ, Ash GJ, Harper JDI, Vipin CA, Raman H, Ellwood S (2014) Identification of QTLs associated with resistance to Phomopsis pod blight (Diaporthe toxica) in Lupinus albus. Breed Sci 64:83-89. https://doi.org/10.1270/jsbbs.64.83

Croxford AE, Rogers T, Caligari PDS, Wilkinson MJ (2008) Highresolution melt analysis to identify and map sequence-tagged site anchor points onto linkage maps: a white lupin (Lupinus albus) map as an exemplar. New Phytol 180:594-607. https://doi.org/10.1111/j. 1469-8137.2008.02588.x
Dangl JL, Jones JD (2001) Plant pathogens and integrated defence responses to infection. Nature 411 doi:https://doi.org/10.1038/ 35081161

Darling AC, Mau B, Blattner FR, Perna NT (2004) Mauve: multiple alignment of conserved genomic sequence with rearrangements. Genome Res 14:1394-1403. https://doi.org/10.1101/gr.2289704

Dubrulle G et al (2020) Phylogenetic diversity and effect of temperature on pathogenicity of Colletotrichum lupini. Plant Dis 104:938-950. https://doi.org/10.1094/pdis-02-19-0273-re

Endelman JB (2011) Ridge regression and other kernels for genomic selection with R package rrBLUP. Plant Genome 4:250-255. https://doi.org/10.3835/plantgenome2011.08.0024

Erdemoglu N, Ozkan S, Tosun F (2007) Alkaloid profile and antimicrobial activity of Lupinus angustifolius L. alkaloid extract. Phytochem Rev 6:197-201. https://doi.org/10.1007/s11101-006-9055-8

Fischer K et al (2015) Characterization and mapping of LanrBo: a locus conferring anthracnose resistance in narrow-leafed lupin (Lupinus angustifolius L.). Theor Appl Genet 128:2121-2130. https://doi.org/ 10.1007/s00122-015-2572-3

Frencel IM (1998) Report on first detection of anthracnose (Colletotrichum gloeosporioides) on lupins in Poland. Plant Dis 82:350-350. https://doi.org/10.1094/PDIS.1998.82.3.350B

Frencel IM, Lewartowska E, Czerwińska A (1997) First report on anthracnose diagnosis and Colletotrichum spp. identification in white lupin (Lupinus albus L.) infection in Poland. Diagnosis and Identification of Plant Pathogens: Proceedings of the 4th International Symposium of the European Foundation for Plant Pathology, September 9-12, 1996, Bonn, Germany. Springer Netherlands, Dordrecht. doi:https://doi.org/10.1007/978-94-0090043-1 63

Gondran J et al (1996) Anthracnose of white lupin (Lupinus albus): European prospects for a future sustainable crop. In: Hill GD (ed) Towards the 21st century. Proceedings of the 8th International Lupin Conference. International Lupin Association, Asilomar, pp 512-518

Hane JK et al (2017) A comprehensive draft genome sequence for lupin (Lupinus angustifolius), an emerging health food: insights into plant-microbe interactions and legume evolution. Plant Biotechnol J 15:318-330. https://doi.org/10.1111/pbi.12615

Harzic N, Huyghe C, Papineau J (1995) Dry matter accumulation and seed yield of dwarf autumn-sown white lupin (Lupinus albus L.). Can J Plant Sci 75:549-555. https://doi.org/10.4141/cjps95-096

Heffner EL, Sorrells ME, Jannink J-L (2009) Genomic selection for crop improvement. Crop Sci 49:1-12. https://doi.org/10.2135/ cropsci2008.08.0512

Heffner EL, Lorenz AJ, Jannink J-L, Sorrells ME (2010) Plant breeding with genomic selection: gain per unit time and cost. Crop Sci 50: 1681-1690. https://doi.org/10.2135/cropsci2009.11.0662

Hufnagel B et al (2020) High-quality genome sequence of white lupin provides insight into soil exploration and seed quality. Nat Commun 11:492. https://doi.org/10.1038/s41467-019-14197-9

Huyghe C, Papineau J (1990) Winter development of autumn sown white lupin: agronomic and breeding consequences. Agronomie 10:709 716. https://doi.org/10.1051/agro:19900902

Jacob I, Feuerstein U, Heinz M, Schott M, Urbatzka P (2017) Evaluation of new breeding lines of white lupin with improved resistance to anthracnose. Euphytica 213:236. https://doi.org/10.1007/s10681017-2011-4

Jarquin D, Kocak K, Posadas L, Hyma K, Jedlicka J, Graef G, Lorenz A (2014) Genotyping by sequencing for genomic prediction in a soybean breeding population. BMC Genomics 15:740. https://doi.org/ 10.1186/1471-2164-15-740

Jones JD (2001) Putting knowledge of plant disease resistance genes to work. Curr Opin Plant Biol 4:281-287. https://doi.org/10.1016/ S1369-5266(00)00174-6 
Julier B, Huyghe C, Papineau J, Milford GFJ, Day JM, Billot C, Mangin $P$ (1993) Seed yield and yield stability of determinate and indeterminate autumn-sown white lupins (Lupinus albus) grown at different locations in France and the UK. J Agric Sci 121:177-186. https://doi.org/10.1017/S0021859600077030

Kearse M et al (2012) Geneious Basic: an integrated and extendable desktop software platform for the organization and analysis of sequence data. Bioinformatics 28:1647-1649. https://doi.org/10.1093/ bioinformatics/bts199

Konieczny A, Ausubel FM (1993) A procedure for mapping Arabidopsis mutations using co-dominant ecotype-specific PCR-based markers. Plant J 4:403-410. https://doi.org/10.1046/j.1365-313X.1993. 04020403.x

Kroc M, Rybiński W, Wilczura P, Kamel KA, Kaczmarek Z, Barzyk P, Święcicki W (2017) Quantitative and qualitative analysis of alkaloids composition in the seeds of a white lupin (Lupinus albus L.) collection. Genet Resour Crop Evol 64:1853-1860. https://doi.org/ 10.1007/s10722-016-0473-1

Książkiewicz M, Yang H (2020) Molecular marker resources supporting the Australian lupin breeding program. In: Singh KB, Kamphuis LG, Nelson MN (eds) The Lupin genome. Springer International Publishing, Cham, pp 73-86. https://doi.org/10.1007/978-3-03021270-4_6

Książkiewicz M et al (2017) A high-density consensus linkage map of white lupin highlights synteny with narrow-leafed lupin and provides markers tagging key agronomic traits. Sci Rep 7:15335. https://doi.org/10.1038/s41598-017-15625-w

Książkiewicz M et al (2020) Validation of Diaporthe toxica resistance markers in European Lupinus angustifolius germplasm and identification of novel resistance donors for marker-assisted selection. J Appl Genet 61:1-12. https://doi.org/10.1007/s13353-019-00521-y

Lambers H, Clements JC, Nelson MN (2013) How a phosphorusacquisition strategy based on carboxylate exudation powers the success and agronomic potential of lupines (Lupinus, Fabaceae). Am J Bot 100:263-288. https://doi.org/10.3732/ajb.1200474

Li X, Renshaw D, Yang H, Yan G (2010) Development of a co-dominant DNA marker tightly linked to gene tardus conferring reduced pod shattering in narrow-leafed lupin (Lupinus angustifolius L.). Euphytica 176:49-58. https://doi.org/10.1007/s10681-010-0212-1

Li X, Yang H, Buirchell B, Yan G (2011) Development of a DNA marker tightly linked to low-alkaloid gene iucundus in narrow-leafed lupin (Lupinus angustifolius L.) for marker-assisted selection. Crop Pasture Sci 62:218-224. https://doi.org/10.1071/CP10352

Li X, Buirchell B, Yan G, Yang H (2012a) A molecular marker linked to the mollis gene conferring soft-seediness for marker-assisted selection applicable to a wide range of crosses in lupin (Lupinus angustifolius L.) breeding. Mol Breed 29:361-370. https://doi.org/ 10.1007/s11032-011-9552-3

Li X, Yang H, Yan G (2012b) Development of a co-dominant DNA marker linked to the gene lentus conferring reduced pod shattering for marker-assisted selection in narrow-leafed lupin (Lupinus angustifolius) breeding. Plant Breed 131:540-544. https://doi.org/ $10.1111 / \mathrm{j} .1439-0523.2012 .01978 . \mathrm{x}$

Lin R et al (2009) Development of a sequence-specific PCR marker linked to the gene "pauper" conferring low-alkaloids in white lupin (Lupinus albus L.) for marker assisted selection. Mol Breed 23:153161. https://doi.org/10.1007/s11032-008-9222-2

Manolio TA et al (2009) Finding the missing heritability of complex diseases. Nature 461:747. https://doi.org/10.1038/nature08494

Meuwissen TH, Hayes BJ, Goddard ME (2001) Prediction of total genetic value using genome-wide dense marker maps. Genetics 157 : $1819-1829$

Nazzicari N, Biscarini F (2017) GROAN: genomic regression workbench. R package version 1.1.0. https://CRAN.R-project.org/ package $=$ GROAN .
Nazzicari N, Biscarini F, Cozzi P, Brummer EC, Annicchiarico P (2016) Marker imputation efficiency for genotyping-by-sequencing data in rice (Oryza sativa) and alfalfa (Medicago sativa). Mol Breed 36:69. https://doi.org/10.1007/s11032-016-0490-y

Neff MM, Neff JD, Chory J, Pepper AE (1998) dCAPS, a simple technique for the genetic analysis of single nucleotide polymorphisms: experimental applications in Arabidopsis thaliana genetics. Plant J 14:387-392. https://doi.org/10.1046/j.1365-313X.1998.00124.x

Neff MM, Turk E, Kalishman M (2002) Web-based primer design for single nucleotide polymorphism analysis. Trends Genet 18:613615. https://doi.org/10.1016/S0168-9525(02)02820-2

Nelson MN et al (2017) The loss of vernalization requirement in narrowleafed lupin is associated with a deletion in the promoter and derepressed expression of a Flowering Locus T (FT) homologue. New Phytol 213:220-232. https://doi.org/10.1111/nph.14094

Nirenberg HI, Feiler U, Hagedorn G (2002) Description of Colletotrichum lupini comb. nov. in modern terms. Mycologia 94: 307-320. https://doi.org/10.2307/3761809

O'Rourke JA et al (2013) An RNA-Seq transcriptome analysis of orthophosphate-deficient white lupin reveals novel insights into phosphorus acclimation in plants. Plant Physiol 161:705-724. https://doi.org/10.1104/pp.112.209254

Osuna-Cruz CM et al (2018) PRGdb 3.0: a comprehensive platform for prediction and analysis of plant disease resistance genes. Nucleic Acids Res 46:D1197-D1201. https://doi.org/10.1093/nar/gkx1119

Papineau J, Huyghe C (2004) Le lupin doux protéagineux. France agricole, Paris

Phan HTT, Ellwood SR, Adhikari K, Nelson MN, Oliver RP (2007) The first genetic and comparative map of white lupin (Lupinus albus L.): identification of QTLs for anthracnose resistance and flowering time, and a locus for alkaloid content DNA. Res 14:59-70. https:// doi.org/10.1093/dnares/dsm009

Plewiński P et al. (2020) Innovative transcriptome-based genotyping highlights environmentally responsive genes for phenology, growth and yield in a non-model grain legume. Plant, Cell Environ: (in press) doi:https://doi.org/10.1111/pce.13880

Raman R, Cowley R, Raman H, Luckett DJ (2014) Analyses using SSR and DArT molecular markers reveal that Ethiopian accessions of white lupin (Lupinus albus L.) represent a unique genepool. Open Journal of Genetics:87-98 doi:https://doi.org/10.4236/ojgen.2014. 42012

Rogers DJ, Tanimoto TT (1960) A computer program for classifying plants. Science 132:1115-1118. https://doi.org/10.1126/science. 132.3434.1115

Romeo FV, Fabroni S, Ballistreri G, Muccilli S, Spina A, Rapisarda P (2018) Characterization and antimicrobial activity of alkaloid extracts from seeds of different genotypes of Lupinus spp. Sustainability 10:788. https://doi.org/10.3390/su10030788

Rychel S, Książkiewicz M (2019) Development of gene-based molecular markers tagging low alkaloid pauper locus in white lupin (Lupinus albus L.). J Appl Genet 60:269-281. https://doi.org/10.1007/ s13353-019-00508-9

Rychel S, Książkiewicz M, Tomaszewska M, Bielski W, Wolko B (2019) FLOWERING LOCUS T, GIGANTEA, SEPALLATA and FRIGIDA homologs are candidate genes involved in white lupin (Lupinus albus L.) early flowering. Mol Breed 39:43. https://doi.org/10. 1007/s11032-019-0952-0

Searle SR, Casella G, McCulloch CE (2008) Variance components. Wiley Series in Probability and Statistics. John Wiley \& Sons, New York. https://doi.org/10.1002/9780470316856

Shavrukov Y (2016) Comparison of SNP and CAPS markers application in genetic research in wheat and barley. BMC Plant Biol 16:11. https://doi.org/10.1186/s12870-015-0689-9

Sokal RR, Michener CD (1958) A statistical method for evaluating systematic relationships. University of Kansas Scientific Bulletin 28: $1409-1438$ 
Sonah H, O'Donoughue L, Cober E, Rajcan I, Belzile F (2015) Identification of loci governing eight agronomic traits using a GBS-GWAS approach and validation by QTL mapping in soya bean. Plant Biotechnol J 13:211-221. https://doi.org/10.1111/pbi. 12249

Stam P (1993) Construction of integrated genetic linkage maps by means of a new computer package: Join Map. Plant J 3:739-744. https:// doi.org/10.1111/j.1365-313X.1993.00739.x

Stekhoven DJ, Bühlmann P (2012) MissForest - non-parametric missing value imputation for mixed-type data. Bioinformatics 28:112-118. https://doi.org/10.1093/bioinformatics/btr597

Sweetingham M, Cowling WA, Buirchell B, Brown A, Shivas R (1995) Anthracnose of lupins in Western Australia. Australas Plant Path 24: 271-271. https://doi.org/10.1071/APP9950271

Sweetingham MW, Yang H, Buirchell BJ, Shea G, Shield I (2005) Resistance to rust in narrow-leafed lupin and development of molecular markers. In: van Santen E, Hill GD (eds) México, where old and new world lupins meet. 11th International Lupin Conference. International Lupin Association, Guadalajara, Mexico, pp 14-16

Talhinhas P, Baroncelli R, Floch GL (2016) Anthracnose of lupins caused by Colletotrichum lupini: a recent disease and a successful worldwide pathogen. J Plant Pathol 98:5-14. https://doi.org/10. 4454/JPP.V98I1.040

Tang D, Ade J, Frye CA, Innes RW (2005) Regulation of plant defense responses in Arabidopsis by EDR2, a PH and START domaincontaining protein. Plant J 44:245-257. https://doi.org/10.1111/j. 1365-313X.2005.02523.x

Thiel T, Kota R, Grosse I, Stein N, Graner A (2004) SNP2CAPS: a SNP and INDEL analysis tool for CAPS marker development. Nucleic Acids Res 32:e5-e5. https://doi.org/10.1093/nar/gnh006

Thomas GJ, Sweetingham MW, Yang HA, Speijers J (2008) Effect of temperature on growth of Colletotrichum lupini and on anthracnose infection and resistance in lupins. Australas Plant Path 37:35-39. https://doi.org/10.1071/AP07075

Untergasser A, Nijveen H, Rao X, Bisseling T, Geurts R, Leunissen JAM (2007) Primer3Plus, an enhanced web interface to Primer3. Nucleic Acids Res 35:W71-W74. https://doi.org/10.1093/nar/gkm306

van Ooijen JW (1992) Accuracy of mapping quantitative trait loci in autogamous species. Theor Appl Genet 84:803-811. https://doi. org $/ 10.1007 / \mathrm{bf00227388}$

Vipin CA et al (2013) Construction of integrated linkage map of a recombinant inbred line population of white lupin (Lupinus albus L.). Breed Sci 63:292-300. https://doi.org/10.1270/jsbbs.63.292

Voorrips RE (2002) MapChart: software for the graphical presentation of linkage maps and QTLs. J Hered 93:77-78. https://doi.org/10.1093/ jhered/93.1.77

Weimer JL (1943) Anthracnose of lupines. Phytopathology 33:249-252

Weimer JL (1952) Lupine anthracnose. Circular No. 904. U.S. Department of Agriculture, Washington D.C.

Yang H, Buirchell B (2008) Strategies in developing molecular markers for marker assisted selection in lupin breeding in Australia. In: Palta JA, Berger JB (eds) Lupins for health and wealth, Proceedings of the 12th International Lupin Conference. International Lupin Association, Canterbury, pp 267-270

Yang H, Sweetingham MW (1998) The taxonomy of Colletotrichum isolates associated with lupin anthracnose. Aust J Agric Res 49: 1213-1224. https://doi.org/10.1071/A98074
Yang H, Shankar M, Buirchell J, Sweetingham W, Caminero C, Smith C (2002) Development of molecular markers using MFLP linked to a gene conferring resistance to Diaporthe toxica in narrow-leafed lupin (Lupinus angustifolius L.). Theor Appl Genet 105:265-270. https://doi.org/10.1007/s00122-002-0925-1

Yang H, Boersma JG, You M, Buirchell BJ, Sweetingham MW (2004) Development and implementation of a sequence-specific PCR marker linked to a gene conferring resistance to anthracnose disease in narrow-leafed lupin (Lupinus angustifolius L.). Mol Breed 14: 145-151. https://doi.org/10.1023/B:MOLB.0000038003.49638.97

Yang H, Renshaw D, Thomas G, Buirchell B, Sweetingham M (2008) A strategy to develop molecular markers applicable to a wide range of crosses for marker assisted selection in plant breeding: a case study on anthracnose disease resistance in lupin (Lupinus angustifolius L.). Mol Breed 21:473-483. https://doi.org/10.1007/s11032-0079146-2

Yang H et al (2010) Development of sequence-specific PCR markers associated with a polygenic controlled trait for marker-assisted selection using a modified selective genotyping strategy: a case study on anthracnose disease resistance in white lupin (Lupinus albus L.). Mol Breed 25:239-249. https://doi.org/10.1007/s11032-009-93254

Yang H, Tao Y, Zheng Z, Li C, Sweetingham MW, Howieson JG (2012) Application of next-generation sequencing for rapid marker development in molecular plant breeding: a case study on anthracnose disease resistance in Lupinus angustifolius L. BMC Genomics 13: 318. https://doi.org/10.1186/1471-2164-13-318

Yang $\mathrm{H}$ et al (2013a) Rapid development of molecular markers by nextgeneration sequencing linked to a gene conferring phomopsis stem blight disease resistance for marker-assisted selection in lupin (Lupinus angustifolius L.) breeding. Theor Appl Genet 126:511522. https://doi.org/10.1007/s00122-012-1997-1

Yang H et al (2013b) Draft genome sequence, and a sequence-defined genetic linkage map of the legume crop species Lupinus angustifolius L. PLoS One 8:e64799. https://doi.org/10.1371/ journal.pone.0064799

Yang $\mathrm{H}$ et al (2015a) Application of whole genome re-sequencing data in the development of diagnostic DNA markers tightly linked to a disease-resistance locus for marker-assisted selection in lupin (Lupinus angustifolius). BMC Genomics 16:660. https://doi.org/ 10.1186/s12864-015-1878-5

Yang H, Li C, Lam HM, Clements J, Yan G, Zhao S (2015b) Sequencing consolidates molecular markers with plant breeding practice. Theor Appl Genet 128:779-795. https://doi.org/10.1007/s00122-0152499-8

You M, Boersma JG, Buirchell BJ, Sweetingham MW, Siddique KHM, Yang H (2005) A PCR-based molecular marker applicable for marker-assisted selection for anthracnose disease resistance in lupin breeding. Cell Mol Biol Lett 10:123-134

Zhou G et al (2018) Construction of an ultra-high density consensus genetic map, and enhancement of the physical map from genome sequencing in Lupinus angustifolius. Theor Appl Genet 131:209223. https://doi.org/10.1007/s00122-017-2997-y

Publisher's note Springer Nature remains neutral with regard to jurisdictional claims in published maps and institutional affiliations. 